\title{
The Impact of Team-Based Primary Care on Guideline-Recommended Disease Screening Julie Fiset-Laniel BSc ${ }^{1,2}$, Mamadou Diop MSc ${ }^{1,2}$, Sylvie Provost MD ${ }^{2}$, Pierre Tousignant MD ${ }^{1,2}$, Erin C. Strumpf PhD ${ }^{1,3,4}$
}

Affiliations: ${ }^{1}$ Department of Epidemiology, Biostatistics \& Occupational Health, McGill University, Montreal, Quebec; ${ }^{2}$ Direction de santé publique du CIUSSS du Centre-Sud-de-l'Île-deMontréal, Montreal, Quebec; ${ }^{3}$ Institut de recherche en santé publique de l'Université de Montréal, Montréal, Québec; ${ }^{4}$ Department of Economics, McGill University, Montreal, Quebec.

Conflict of interest statement: Julie Fiset-Laniel, Mamadou Diop, Sylvie Provost, Pierre Tousignant and Erin Strumpf have no conflicts of interest to disclose. This research project was funded by the Canadian Institutes of Health Research (CIHR) grant numbers MOP 93546 and MOP 123278. ES was supported by a Chercheur boursier Junior 2 from the Fonds de la recherche du Québec-Santé. Funders had no role in study design; collection, analysis, and interpretation of data; writing the report; or the decision to submit the report for publication.

No financial disclosures were reported by the authors of this paper.

\section{Corresponding author:}

Erin C. Strumpf

McGill University

1020, avenue des Pins

Montréal (Québec)

Canada

$\mathrm{H} 3 \mathrm{~A} 1 \mathrm{~A} 2$

Tel : 514-398-2880

erin.strumpf@mcgill.ca 
Abstract

Introduction: Family Medicine Groups (FMGs), implemented in Quebec in 2002, are interprofessional primary care teams designed to improve timely access to high-quality primary care. The authors investigate whether FMGs increased rates of guideline-recommended screenings for three chronic diseases: colorectal cancer (colon/sigmoidoscopy), breast cancer (mammography), and osteoporosis (bone mineral density (BMD) test).

Methods: Using population-based administrative health data from the provincial insurer (2000-2010), the authors examined elderly and chronically ill patients who registered with a general practitioner (GP) in the first 15 months of the FMG policy. They used propensity score weighting and a differencein-differences (DD) model to estimate any differential change in biennial screening rates among FMG and non-FMG patients over 5 years of follow-up (analysis 2016-2018).

Results: Rates of mammography, colon/sigmoidoscopy, and BMD testing increased after patient registration with a GP, similarly for both FMG and non-FMG patients. Colon/sigmoidoscopy rates increased by $9.7 \%$ and $10.4 \%$ for FMG and non-FMG patients, respectively; mammography rates by $5.3 \%$ and $3.4 \%$; BMD testing by $4.2 \%$ and $7.1 \%$. Our DD estimates show no detectable effect of FMGs on disease screening rates: -0.06 percentage points $(95 \% \mathrm{CI}-0.32 ; 0.20)$ for colon/sigmoidoscopy, 1.01 percentage points $(95 \% \mathrm{CI}-0.25 ; 2.27)$ for mammography, and $-0.32(95 \% \mathrm{CI}-0.71 ;-0.07)$ for $\mathrm{BMD}$ testing.

Conclusions: The authors found no evidence that FMGs affected screening rates for these three chronic diseases. Limitations in the implementation of the FMG policy in its early years may have contributed to this lack of impact. Interprofessional primary care teams may need to include elements other than organizational changes in order to increase disease prevention efforts. 


\section{Introduction}

Despite wide diversity in their health care systems, developed countries face the challenges of improving population health, ensuring access to high-quality health services, and containing health care costs, all in the context of a growing burden of chronic diseases. Disease prevention and health promotion are often-proposed parts of the solution, since early detection of chronic diseases can have a positive impact on future morbidity and mortality. ${ }^{1-6}$ However, rates of guideline-recommended disease screening often remain suboptimal. ${ }^{78}$ Approximately $18 \%$ of eligible patients receive timely colorectal cancer screening across four Canadian provinces and less than half of Canadians age $65+$ were screened at least once for osteoporosis by bone mineral density (BMD) testing. ${ }^{9}{ }^{10}$ In Quebec, breast cancer screening program participation rates increased from $43 \%$ to $54 \%$ between 1998 and $2008^{4}$, below the target of $70 \% .^{11}$

Primary health care providers can play active roles in prevention: by complementing organized screening initiatives, recommending appropriate screening tests for at-risk patients, and facilitating access to, or directly providing, these services. ${ }^{12}$ Having a regular source of care is strongly associated with receiving disease screening, including cancer screening. ${ }^{913-17}$ Some studies show that primary care clinics with integrated nurse practitioners provide more preventive services and screening, ${ }^{18} 19$ while others find no such association. ${ }^{20}$ The characteristics of primary care organizations may also affect receipt of preventive care. Among patients with a regular source of primary care, the convenience of timely access to care at a primary care office is associated with higher odds of prostate examination, flu-shot and cholesterol tests, but not mammography. ${ }^{21}$ Teamwork characteristics ${ }^{22}{ }^{23}$ and comprehensiveness of care ${ }^{24}$ are also associated with screening, counselling, and immunization.

Primary care reforms worldwide ${ }^{25-27}$ and in Canada $^{2829}$ over the last two decades attempted to harness this potential for high-quality primary care to improve access to care and population health outcomes, 
including disease screening and prevention. In addition to integrating health promotion and illness prevention strategies, high-quality interprofessional primary care teams usually include patient rostering, timely access to a comprehensive range of primary care services, specialist referral, blended payment and integration of electronic medical records. ${ }^{30} 31$ Additional financial commitments are being made to support patient enrolment with primary care teams in Quebec, with the goal of improving access to high-quality primary care. ${ }^{32} 33$

\section{Family Medicine Groups: Quebec's interprofessional, team-based primary care model}

Quebec has universal public insurance coverage for physician and hospital services, with no patient cost sharing for these services. General practitioners (GP) are usually paid on a fee-for-service (FFS) basis, with some small additional incentive payments to enroll patients, particularly those with chronic

conditions. In response to recommendations by Quebec's Commission on Health and Social Services, ${ }^{30}$ and inspired by primary care models in Ontario and in Sweden, ${ }^{34}$ Quebec's Health Ministry reorganized primary care service delivery creating Family Medicine Groups (FMGs) in late 2002. FMG's are designed to include a team of 6-12 full-time equivalent GPs working closely with a nurse practitioner, and sometimes with other health professionals. FMGs do not affect the FFS remuneration, but add a modest annual premium per enrolled patient (\$7 during the study period). In return, the FMG GP agrees to be in charge of the patient's care, ensure follow-up of his health problems, and offer a wide range of services, including preventive care. Nurses, whose salaries are paid by the Health Ministry, are integrated within each group. The intention is that they participate in health promotion, disease prevention, and case management, and facilitate links with specialists and community health centers. ${ }^{3536}$ The FMG policy also includes evening/weekend open hours and on-call medical services. While the design of the FMG policy was consistent across the province, there was notable variation in the characteristics across FMGs and the extent to which they implemented the policy as intended. ${ }^{34} 37$ In 2015, Quebec's Inspector General cited the lack of clear targets and indicators, as well as monitoring 
and enforcement, as contributing to this variation and to the modest changes in service delivery relative to expectations. ${ }^{37}$

Despite the fact that FMGs were designed to have the characteristics shown to be associated with better care processes, ${ }^{1516} 18212430$ existing evidence on their impacts has shown limited benefits. One study showed that receipt of preventive care overall was higher for patients in FMGs than patients in nonFMG clinics. ${ }^{16}$ FMGs were also associated with higher rates of colorectal cancer screening, but not mammography. To the authors' knowledge, only one study provided plausibly causal estimates of the impact of the FMG model on preventive health services use. Using data on the deployment of FMGs by health region combined with a population-representative survey, Dunkley-Hickin et al. ${ }^{38}$ found no impact of FMGs across the province on reported receipt of preventive services including flu shots, Pap tests, or screening mammography for eligible patients.

\section{Contributions}

While conceptual frameworks support the idea that "better" primary care will improve access, use of preventive services, and health outcomes, empirical analyses are needed to measure the impacts of policy reforms as actually implemented. As a step towards filling this gap, this analysis estimates the impact of the FMG policy on the delivery of preventive care between November 2002 and January 2010. The authors hypothesised that FMGs will have a positive impact on rates of guideline-consistent disease screening for FMG patients compared to those enrolled in traditional clinics, specifically for colonoscopy or sigmoidoscopy, mammography, and BMD testing.

\section{Methods}

\section{Study Population and Data}


The authors conducted a retrospective cohort study of elderly and/or chronically ill $^{1}$ patients who registered with a GP in Quebec during the first 27 months of the FMG policy (November 2002 to January 2005). Because all physicians, whether or not they work in a FMG, received a bonus per examination for enrolled patients, the authors expect to capture nearly all patients who meet the eligibility criteria and see a GP during this period. The database comprises data for each individual 2 years before and 5 years after their enrollment with a GP (2000-2010).

The authors analyzed population-based billing data from Quebec's provincial public insurer, the Régie de l'assurance maladie du Québec. These data contain information on individual-level demographics and health care services utilization including physicians' services, hospital admissions and emergency department visits. Data on lab tests (e.g. fecal occult blood testing (FOBT)), are not included because most are not billed separately. The assessment of service utilization related to disease screening guidelines was limited to four billable preventive services: colonoscopy or sigmoidoscopy, mammography and BMD. Use of the data was authorized by Quebec's Commission d'accès à l'information, and was analyzed in 2016-2018. The study protocol was approved by the McGill Faculty of Medicine IRB.

\section{Measures}

The authors created indicator variables for receipt of colon/sigmoidoscopy, mammography, and BMD testing in the past 2 years (biennially). Individuals were considered eligible for cancer and osteoporosis screening based on their age, sex, and health status, following the clinical guidelines applicable during the study period (Table 1). For each screening test, they calculated a rate of receipt at least once in the two years before enrollment with a GP, and 4 biennial rates during the 5 years of follow-up (years $1 \&$

\footnotetext{
${ }^{1}$ The cohort includes patients considered "vulnerable" by Quebec's insurer. They are either 70 years old or above, or have at least one the following conditions (at any age): psychosis, chronic obstructive pulmonary disease (COPD), moderate to severe asthma, pneumonia, cardiovascular disease, cancer associated with past, present or future chemotherapy or radiotherapy treatments, cancer in a terminal phase, diabetes, alcohol or hard drug withdrawal, drug addiction treated with methadone, HIV/AIDS, or a degenerative disease of the nervous system. ${ }^{37}$
} 
$2,2 \& 3$, etc.). Eligible patients were men and women age 50 and over (colon/sigmoidoscopy), women age 50 to 69 (mammography), and women age 65 and over (BMD). Patients with at least one diagnostic code during the study period for colorectal or breast cancer or osteoporosis or a frailty fracture were excluded from the relevant denominator, to maximize the probability that screening tests are captured, rather than follow-up or treatment (Appendix A).

The authors created two indicator variables: one for the treatment group (enrollment with a GP in $(\mathrm{FMG}=1)$ or outside an FMG $(\mathrm{FMG}=0)$, another indicating the period after enrollment $(\mathrm{Post}=1)$ or before $($ Post $=0$ ). The exposure is being in the treatment group in the post-enrollment period, represented by the interaction of FMG and Post. Covariates include patient age, sex, geographic region, calendar year, and SES (quintiles of the Pampalon material deprivation index). ${ }^{40}$ The geographic area variable is inspired by the work of Gauthier et al., ${ }^{41}$ who categorize Quebec's health regions according to their urbanity and health care resources. The resource utilization band (RUB) is a 6-level categorical variable that captures morbidity based on diagnostic codes and Adjusted Clinical Groups for each patient in the previous 12 months. ${ }^{42}$ Patients in the same RUB category do not necessarily have clinically-related diagnoses, but their expected relative resource use is similar.

\section{Statistical Analysis}

The authors calculate screening rates among eligible patients in the two years before enrollment with a GP and describe how they vary according to patient characteristics. They then use propensity scores (PS) to make the FMG and non-FMG groups as similar as possible at enrollment to address potential selection bias. Patients who enrolled in FMGs were more likely to be female, live in lower SES neighbourhoods, and to visit the emergency department and to be hospitalized for any cause before enrollment. ${ }^{43}$ The PS model included demographics (age, SES, geographic area and sex), morbidity 
indicators (RUB, diabetes, high blood pressure, asthma, heart failure, anxiety or depressive disorder), public prescription drug coverage, and health services use.

The third part of the analysis estimates the impact of the FMG policy on the rates of disease screening using a difference-in-difference (DD) model. The DD model compares change over time in outcomes for a treated group (FMG patients) and a control group (non-FMG patients), removing potential bias related to common temporal trends in the outcomes and time-invariant unmeasured differences between the groups (Appendix B). Patients eligible for screening during all seven years of follow-up were included. Patients who died, moved between types of geographic areas, or entered long-term care were excluded, and rates of loss-to-follow-up were nearly identical in the FMG and non-FMG groups. The authors used the PS to adjust the sample using inverse probability of treatment weighting (IPTW), and restricted to the range of common support of the PS. ${ }^{44}$

\section{Results}

\section{Descriptive analysis}

Table 2 summarizes unadjusted rates of disease screening among eligible patients before enrollment with a GP by patient characteristics. The biennial screening rates before enrollment are $7.6 \%$ for colon/sigmoidoscopy, $49.0 \%$ for mammography and $8.3 \%$ for BMD testing. Colon/sigmoidoscopy rates are similar between FMG patients and non-FMG, but mammography and BMD testing rates are slightly higher for FMG patients ( $52.2 \%$ vs. $48.4 \%$ and $9.2 \%$ vs. $8.1 \%$, respectively).

Colon/sigmoidoscopy rates are highest in the highest SES areas (9.0\%) and there is a clear positive gradient with morbidity and diagnosed chronic conditions. Mammography rates are stable across eligible age groups and are lower in the intermediate geographic regions (41.2\%), in the lower SES areas $(44.2 \%)$, and among patients with lower morbidity (46.9\%). There are clear gradients in BMD testing rates, which decrease substantially with age, geographic remoteness, and socioeconomic disadvantage. Patients with moderate or high morbidity have higher rates of BMD testing. 


\section{Propensity score adjustment}

For all three diseases, screening rates vary by patients' SES, morbidity, and chronic illness diagnoses. These characteristics also vary by FMG status ${ }^{43}$ (Table 3 ). This demonstrates the importance of baseline PS adjustment to reduce bias in the estimated effect of FMG enrollment on disease screening. After IPTW adjustment, there are no important differences between the treatment and control groups (Table 3).

\section{Difference-in-differences analysis}

Predicted rates of screening test use from the DD model, as well as the DD effect estimates, are shown in Figure 1. After IPTW adjustment and direct control for covariates, rates of disease screening increase for both FMG and non-FMG patients after enrollment with a GP. The proportion of eligible patients receiving colon/sigmoidoscopy increased 10.4\% for FMG patients (from 7.7\% to 8.5\%), and by $10.3 \%$ for non-FMG patients (from $7.8 \%$ to $8.6 \%$ ). Mammography rates increased by $5.3 \%$ for FMG and 3.4\% for non-FMG patients. Finally, rates of BMD testing increased 4.4\% for FMG and $7.1 \%$ for non-FMG patients.

For the chronic conditions considered, the authors found no detectable effect of enrollment in a FMG on rates of disease screening. That is, the increase in the post-enrollment period wasn't different for FMG patients compared to non-FMG patients. The null estimated effect of the FMG policy on disease screening is demonstrated by the DD estimates, which are small and not statistically significant at $\mathrm{p}<=0.05$ (BMD testing is borderline): -0.06 95\%CI [-0.32;0.19] for colon/sigmoidoscopy, $1.0195 \% \mathrm{CI}$ $[-0.25 ; 2.27]$ for mammography and $-0.3195 \% \mathrm{CI}[-0.70 ; 0.09]$ for BMD testing.

\section{Discussion}

After enrolling with a GP, service utilization related to disease screening guidelines increased for all patients, and this increase was equivalent in FMGs and non-FMGs. This suggests no impact of 
enrollment in early FMGs on rates of disease screening, and suggests that enrollment with a GP alone may play an important role in disease screening ${ }^{45}$. The results are consistent with other published data which show increases in breast cancer screening ${ }^{46}$ and relatively low screening rates for colorectal cancer. ${ }^{8}$ Increased rates of treatment consistent with clinical guidelines for diabetes, hypertension and ischemic heart disease after enrollment with a GP has previously been documented using the same dataset. ${ }^{47}$ Results from this study are also consistent with existing evidence on Quebec's FMG policy, which has documented modest-to-null impacts of FMGs on health services utilization, ${ }^{47-49}$ related $\operatorname{costs}^{49}$ and accessibility to primary care. ${ }^{3850} 51$

Unlike primary health care reforms implemented in other Canadian provinces, Quebec's primary care reform focused on organizational changes. It did not change physician payment from FFS and included only small extra payments for patient enrollment. FFS tends to discourage low-cost alternatives to health care delivery by physicians - including preventive services delivery - in contrast with more prospective modes of remuneration. ${ }^{5253}$ Therefore, the findings of this study may be partly explained by the absence of blended payment, including capitation and pay for performance. However, the experiences of Ontario and British Columbia suggest little-to-no impact of pay-for-performance incentives on rates of disease screening for at-risk populations. ${ }^{54-56}$

In her 2015 annual report, the Quebec Auditor General ${ }^{37}$ highlighted weaknesses in the FMG policy as it was actually implemented, notably the lack of clear targets, monitoring, and enforcement. Three elements may have contributed to the lack of impact of FMGs on rates of disease screening. First, as of March 2014, less than $60 \%$ of FMGs met the requirements of being open after 5pm and on weekends. Second, improved links between FMGs and specialists, an explicit goal of the FMG policy, largely did not materialize. Thus, barriers to screening remained, since services like mammography, endoscopy, and blood tests are provided in centers outside the primary care clinic. Third, some of the nurses hired 
in FMGs were not qualified as nurse practitioners, limiting their capacity to play an advanced clinical role and deliver preventive health services. Some FMGs did not replace qualified nurses on sick or maternity leave, potentially leaving patients without appropriate nurse follow-up. Further attention to issues including health human resources, the work life of health care providers, and facilitators and barriers to links across providers may be needed.

\section{Strengths and limitations}

An important limitation of this study is that rates of screening for colon cancer, excluding FOBT, and osteoporosis were measured over 2 years, instead of the guideline-recommended timing of 5 years, due to data availability. While these will underestimate the rate of guideline-consistent disease screening, it is unlikely to be differential between the two groups. The comparison of biennial rates between FMG and non-FMG patients is still valuable and is consistent with other evaluations of preventive screening interventions. ${ }^{57-59}$ While insurance claims data are not sensitive to recall bias, they may be influenced by coding patterns ${ }^{60}$ and reflect realized access to screening tests rather than recommendations by health care professionals, weaknesses the authors expect to apply similarly in the treatment and comparison groups. The difference-in-differences model controls for fixed unobserved differences between FMG and non-FMG practices. Time-varying unobserved confounders, such as differential evolution in organizational readiness to change, could bias the estimates. Lastly, the authors are not able to definitively characterize the use of tests as screening vs. treatment/follow-up. They maximize the probability of capturing screening by removing patients with relevant diagnoses from the denominators.

The main strength of this study is the use of rigorous empirical methods to estimate the impact of FMGs on disease screening. The authors used PS adjustment in order to make the treatment and control groups equivalent at baseline, thus reducing confounding bias. They estimated the effects of the FMG 
reform using a difference-in-differences model, allowing them to control for fixed differences and common time trends in the two groups. The risk of cross-contamination between the two groups was minimal since a minority of patients and GPs were in FMGs in the first few years after the reform. This study is the first to estimate the impact of the beginning of the FMG model on the delivery of guideline-consistent disease screening using physician billing claims. The results are of particular interest given Quebec's financial commitments to implement a new generation of "network FMGs". ${ }^{32}$

${ }^{33}$ While jurisdiction-specific contextual factors may vary, many of the structural characteristics of FMGs are similar to patient-centered medical homes in other jurisdictions,${ }^{61}$ making these findings potentially applicable to other health care systems. The results suggest that primary care teams will have to include elements other than organizational changes in order to increase disease prevention efforts, potentially including financial or cultural changes. Future research including process evaluation to better understand the implementation, mechanisms, and contextual factors could add important complimentary knowledge.

\section{Conclusions}

The authors found no evidence to support their hypothesis that FMGs would have a positive impact on rates of disease screening among eligible patients. In fact, they estimated null effects of FMG enrollment on biennial rates of screening services measurable in Quebec's billing data colon/sigmoidoscopy, mammography and BMD testing - over 5 years of follow-up. The limited impact of Quebec's primary care reform on disease screening should be interpreted in the context of unequal and difficult implementation of FMGs across Quebec, and the absence of financial incentives. 


\section{Acknowledgements}

The authors would like to thank the former research team Santé des populations et des services de santé of the Direction de santé publique de Montréal, and the Institut national de santé publique du Québec. This research project was funded by the Canadian Institutes of Health Research (CIHR) grant numbers MOP 93546 and MOP 123278. ES was supported by a Chercheur boursier Junior 2 from the Fonds de la recherche du Québec-Santé. 
Figure 1.

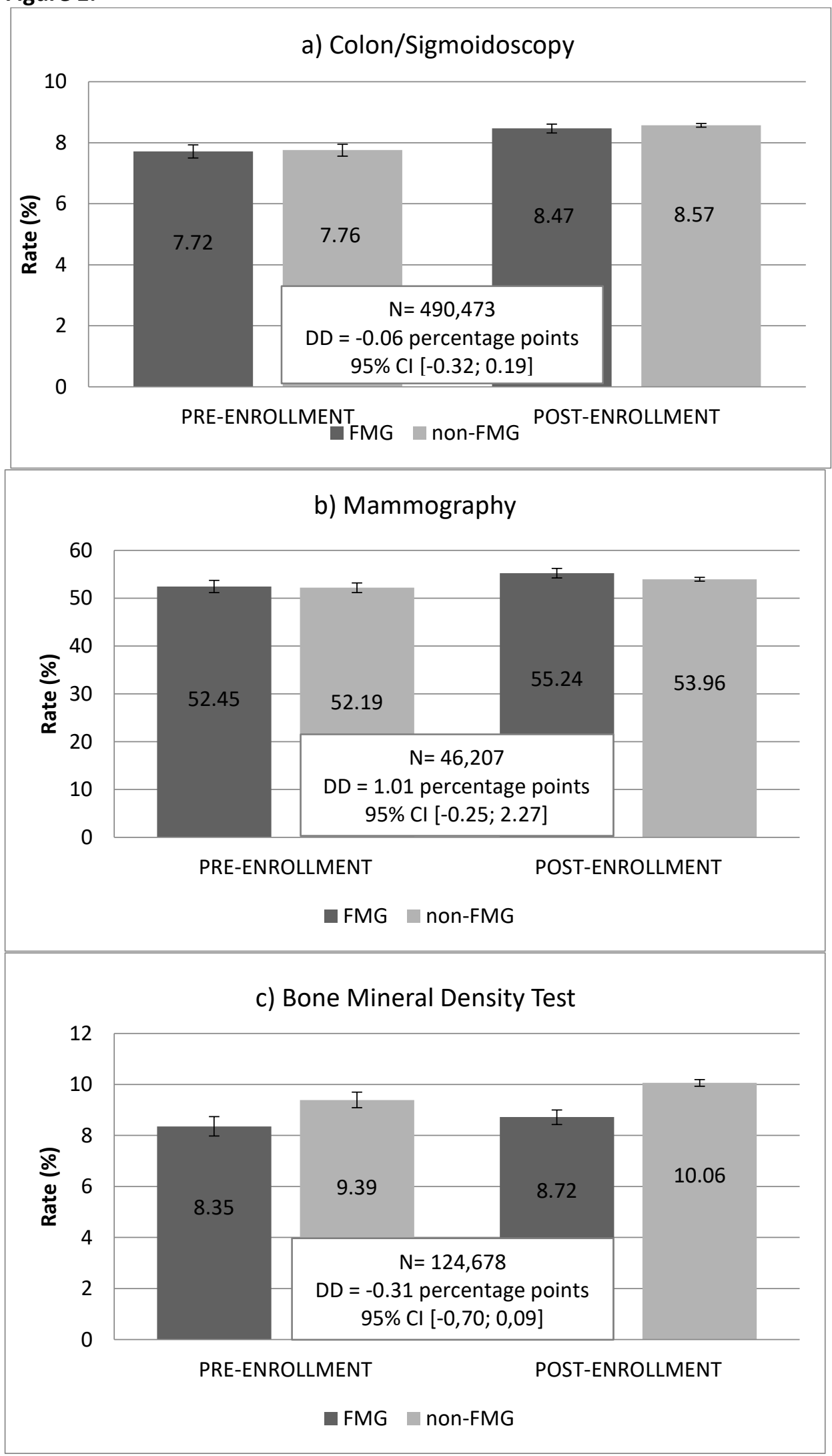

DD: difference-in-differences estimate; $\mathrm{Cl}$ : confidence interval 
Table 1. Disease screening guidelines and target populations

\begin{tabular}{|c|c|c|c|c|c|c|c|}
\hline $\begin{array}{l}\text { Disease } \\
\text { Screening }\end{array}$ & $\begin{array}{l}\text { Recommended } \\
\text { Preventive Care }\end{array}$ & $\begin{array}{l}\text { RAMQ } \\
\text { Billing Codes }\end{array}$ & $\begin{array}{l}\text { Target } \\
\text { Population }\end{array}$ & Exclusions $^{a}$ & $\begin{array}{l}\text { Recommended } \\
\text { Frequency }\end{array}$ & $\begin{array}{l}\text { Measured } \\
\text { Frequency }\end{array}$ & Reference \\
\hline $\begin{array}{l}\text { Colorectal } \\
\text { cancer } \\
\text { screening }\end{array}$ & $\begin{array}{l}\text { Colonoscopy } \\
\text { or } \\
\text { flexible } \\
\text { sigmoidoscopy } \\
\text { or FOBT }^{\text {a }}\end{array}$ & $\begin{array}{l}\text { Colonoscopy: } \\
00697 \\
00700 \\
00703 \\
00749 \\
00750 \\
00863 \\
\text { Sigmoidoscopy: } \\
00635 \\
00636 \\
00706\end{array}$ & $\begin{array}{l}\text { Men and } \\
\text { women age } \\
50+\end{array}$ & $\begin{array}{l}\text { Patients } \\
\text { diagnosed with } \\
\text { colorectal } \\
\text { cancer }\end{array}$ & $\begin{array}{l}\text { Every } 5 \text { years if } \\
\text { sigmoidoscopy } \\
\text { only } \\
\text { Every } 10 \text { years } \\
\text { if colonoscopy } \\
\text { Every } 2 \text { years if } \\
\text { FOBT }\end{array}$ & Every 2 years & $\begin{array}{l}\text { Desmond, et } \\
\text { al. } 6\end{array}$ \\
\hline $\begin{array}{l}\text { Breast } \\
\text { cancer } \\
\text { screening }\end{array}$ & Mammography & $\begin{array}{l}08079 \\
08146\end{array}$ & $\begin{array}{l}\text { Women age } \\
50 \text { to } 69\end{array}$ & $\begin{array}{l}\text { Women } \\
\text { diagnosed with } \\
\text { breast cancer }\end{array}$ & Every 2 years & Every 2 years & $\begin{array}{l}\text { Ministère de } \\
\text { la Santé et des } \\
\text { Services } \\
\text { sociaux } 62\end{array}$ \\
\hline $\begin{array}{l}\text { Osteoporosis } \\
\text { screening }\end{array}$ & $\begin{array}{l}\text { Bone mineral } \\
\text { density test }\end{array}$ & $\begin{array}{l}08243 \\
08245 \\
08246\end{array}$ & $\begin{array}{l}\text { Women age } \\
65+\end{array}$ & $\begin{array}{l}\text { Women } \\
\text { diagnosed with } \\
\text { osteoporosis or } \\
\text { identified with } \\
\text { a fragility } \\
\text { fracture }\end{array}$ & Every 5 years & Every 2 years & Brown, et al. 5 \\
\hline
\end{tabular}

RAMQ: Régie de l'assurance maladie du Québec

Note ICD and billing codes used as exclusion criteria for calculation of preventive screening rates are listed in Appendix A.

aFecal occult blood (FOBT) test can't be measured in billing claims because they are not billed separately under Quebec's FFS schedule. 
Table 2. Unadjusted biennial disease screening rates before enrollment with a GP, by patient characteristics

\begin{tabular}{|c|c|c|c|c|c|c|c|c|c|}
\hline \multirow{3}{*}{$\begin{array}{l}\text { Patient } \\
\text { Characteristics }\end{array}$} & \multicolumn{3}{|c|}{ Colonoscopy/sigmoidoscopy } & \multicolumn{3}{|c|}{ Mammography } & \multicolumn{3}{|c|}{ Bone Mineral Density Test } \\
\hline & \multirow{2}{*}{$\begin{array}{c}\text { Eligible for } \\
\text { screening } \\
\text { No. }\end{array}$} & \multicolumn{2}{|c|}{ Receiving screening } & \multirow{2}{*}{$\begin{array}{c}\text { Eligible for } \\
\text { screening } \\
\text { No. }\end{array}$} & \multicolumn{2}{|c|}{$\begin{array}{l}\text { Receiving } \\
\text { screening }\end{array}$} & \multirow{2}{*}{$\begin{array}{c}\text { Eligible for } \\
\text { screening } \\
\text { No. }\end{array}$} & \multicolumn{2}{|c|}{$\begin{array}{l}\text { Receiving } \\
\text { screening }\end{array}$} \\
\hline & & $\%$ & SD & & $\%$ & SD & & $\%$ & SD \\
\hline All & 490,473 & 7.59 & & 46,207 & 49.03 & 49.99 & 124,678 & 8.30 & 27.59 \\
\hline \multicolumn{10}{|c|}{ Primary care model } \\
\hline FMG & 75,463 & 7.55 & 26.49 & 7,293 & 52.24 & 49.95 & 19,897 & 9.21 & 28.91 \\
\hline Non-FMG & 415,010 & 7.59 & 26.42 & 38,914 & 48.43 & 49.98 & 104,781 & 8.13 & 27.32 \\
\hline \multicolumn{10}{|l|}{ Sex } \\
\hline Male & 282,624 & 7.60 & 26.51 & & & & & & \\
\hline Female & 207,849 & 7.57 & 26.46 & 46,207 & 49.03 & 49.99 & 124,678 & 8.30 & 27.59 \\
\hline \multicolumn{10}{|l|}{ Age } \\
\hline $50-54$ & 26,524 & 6.20 & 24.11 & 10,660 & 48.37 & 49.98 & & & \\
\hline $55-59$ & 43,214 & 6.81 & 25.20 & 17,058 & 49.88 & 50.00 & & & \\
\hline $60-64$ & 46,200 & 8.03 & 27.18 & 18,489 & 48.63 & 49.98 & & & \\
\hline $65-69$ & 82,429 & 8.48 & 27.87 & & & & 21,374 & 12.73 & 33.33 \\
\hline $70-74$ & 138,122 & 8.07 & 27.24 & & & & 43,976 & 9.97 & 29.96 \\
\hline $75-79$ & 91,325 & 7.65 & 26.58 & & & & 32,845 & 6.91 & 25.36 \\
\hline $80-84$ & 45,100 & 6.47 & 24.60 & & & & 18,362 & 4.50 & 20.74 \\
\hline 85 and over & 17,559 & 4.94 & 21.68 & & & & 8,121 & 1.79 & 13.24 \\
\hline \multicolumn{10}{|c|}{ Geographic Region } \\
\hline University & 181,539 & 8.06 & 27.22 & 15,668 & 49.41 & 50.00 & 47,370 & 10.95 & 31.22 \\
\hline Suburban & 187,063 & 7.30 & 26.01 & 18,649 & 52.82 & 49.92 & 45,737 & 8.47 & 27.85 \\
\hline Intermediate & 101,069 & 7.17 & 25.80 & 9,551 & 41.25 & 49.23 & 25,511 & 4.75 & 21.28 \\
\hline Rural & 20,802 & 8.06 & 27.22 & 2,339 & 48.10 & 49.97 & 6,060 & 1.22 & 10.98 \\
\hline \multicolumn{10}{|l|}{$\begin{array}{l}\text { Socioeconomic } \\
\text { Status }\end{array}$} \\
\hline $\begin{array}{l}\text { Q1 'Most } \\
\text { advantaged' }\end{array}$ & 77,529 & 9.01 & 28.64 & 5,991 & 52.23 & 49.95 & 18,568 & 12.01 & 32.51 \\
\hline Q2 & 86,721 & 7.68 & 26.63 & 7,973 & 51.89 & 49.97 & 21,363 & 9.61 & 29.47 \\
\hline Q3 & 99,071 & 7.33 & 26.06 & 9,439 & 51.28 & 49.99 & 24,532 & 7.86 & 26.91 \\
\hline
\end{tabular}




\begin{tabular}{|c|c|c|c|c|c|c|c|c|c|}
\hline Q4 & 103,832 & 7.11 & 25.70 & 10,386 & 48.58 & 49.98 & 26,506 & 7.64 & 26.57 \\
\hline $\begin{array}{l}\text { Q5 'Most } \\
\text { disadvantaged' }\end{array}$ & 102,617 & 7.24 & 25.91 & 10,874 & 44.19 & 49.66 & 27,500 & 5.88 & 23.53 \\
\hline Missing & 20,703 & 7.20 & 25.84 & 1,544 & 45.34 & 49.79 & 6,209 & 7.94 & 27.04 \\
\hline \multicolumn{10}{|l|}{ Morbidity (RUB) } \\
\hline Non-User & 18,655 & 1.40 & 11.77 & 1,182 & 32.49 & 46.85 & 6,056 & 3.93 & 19.43 \\
\hline Healthy User & 15,461 & 2.65 & 16.05 & 1,183 & 46.91 & 49.93 & 4,861 & 7.63 & 26.55 \\
\hline Low Morbidity & 78,244 & 3.19 & 17.58 & 6,370 & 45.70 & 49.82 & 23,626 & 7.31 & 26.02 \\
\hline Moderate Morbidity & 289,997 & 7.96 & 27.07 & 28,079 & 50.74 & 50.00 & 73,388 & 9.03 & 28.66 \\
\hline High Morbidity & 59,665 & 11.77 & 32.22 & 6,289 & 49.04 & 49.99 & 11,757 & 8.91 & 28.50 \\
\hline Very High Morbidity & 28,451 & 13.79 & 34.47 & 3,104 & 47.55 & 49.95 & 4,990 & 6.73 & 25.06 \\
\hline \multicolumn{10}{|l|}{ Diagnoses } \\
\hline Diabetes & 82,695 & 7.81 & 26.83 & 11,705 & 47.14 & 49.92 & 17,883 & 6.34 & 24.36 \\
\hline Hypertension & 193,816 & 8.39 & 27.72 & 15,300 & 49.67 & 50.00 & 59,524 & 7.95 & 27.05 \\
\hline $\mathrm{COPD}^{\mathrm{b}}$ & 44,025 & 9.93 & 29.91 & 5,656 & 45.40 & 49.79 & 8,065 & 6.35 & 24.38 \\
\hline Asthma & 20,010 & 10.72 & 30.94 & 4,790 & 51.38 & 49.99 & 3,809 & 10.29 & 30.39 \\
\hline Cardiac insufficiency & 13,661 & 10.77 & 31.00 & 1,042 & 43.76 & 49.63 & 3,237 & 4.26 & 20.21 \\
\hline $\begin{array}{l}\text { Ischemic heart } \\
\text { disease }\end{array}$ & 94,425 & 9.66 & 29.54 & 8,365 & 49.50 & 50.00 & 16,855 & 6.86 & 25.28 \\
\hline $\begin{array}{l}\text { Depression or anxiety } \\
\text { disorder }\end{array}$ & 55,824 & 10.67 & 30.88 & 9,406 & 47.53 & 49.94 & 13,599 & 9.15 & 28.83 \\
\hline
\end{tabular}

${ }^{b}$ COPD = Chronic obstructive pulmonary disease

SD is standard deviation 
Table 3. Baseline characteristics of patients eligible for at least one of the disease screening tests measured

\begin{tabular}{|c|c|c|c|c|c|c|}
\hline \multirow{2}{*}{$\begin{array}{l}\text { Patient Characteristics } \\
\text { All patients }\end{array}$} & \multicolumn{3}{|c|}{ Unweighted } & \multicolumn{3}{|c|}{ Weighted } \\
\hline & $\begin{array}{c}\text { Total } \\
(\mathrm{n}=\mathbf{5 0 9 , 8 3 7}) \\
\% \mathbf{( S E )}\end{array}$ & $\begin{array}{c}\text { FMG } \\
(n=78,467) \\
\%(S E)\end{array}$ & $\begin{array}{c}\text { Non-FMG } \\
(n=431,370) \\
\%(S E)\end{array}$ & $\begin{array}{c}\text { Total } \\
(\mathrm{n}=\mathbf{5 0 9 , 8 3 7 )} \\
\% \text { \% (SE) }\end{array}$ & $\begin{array}{c}\text { FMG } \\
(\mathrm{n}=78,467) \\
\%(\mathrm{SE})\end{array}$ & $\begin{array}{c}\text { Non-FMG } \\
(n=431,370) \\
\%(S E)\end{array}$ \\
\hline \multicolumn{7}{|l|}{ Sex } \\
\hline \multicolumn{7}{|l|}{ Age } \\
\hline $\begin{array}{l}50-54 \\
55-59 \\
60-64\end{array}$ & $\begin{array}{l}5.3(0.03) \\
8.8(0.04) \\
9.4(0.04)\end{array}$ & $\begin{array}{l}5.6(0.08) \\
8.9(0.10) \\
9.6(0.11)\end{array}$ & $\begin{array}{l}5.3(0.03) \\
8.7(0.04) \\
9.4(0.04)\end{array}$ & $\begin{array}{l}5.4(0.03) \\
8.9(0.04) \\
9.5(0.04)\end{array}$ & $\begin{array}{l}5.4(0.08) \\
9.0(0.10) \\
9.5(0.10)\end{array}$ & $\begin{array}{l}5.4(0.03) \\
8.8(0.04) \\
9.4(0.04)\end{array}$ \\
\hline $\begin{array}{l}65-69 \\
70-74 \\
75-79 \\
80-84 \\
85 \text { and over }\end{array}$ & $\begin{array}{c}16.8(0.05) \\
28.1(0.06) \\
18.7(0.05) \\
9.2(0.04) \\
3.6(0.03)\end{array}$ & $\begin{array}{c}17.4(0.14) \\
27.3(0.16) \\
18.7(0.14) \\
9.1(0.10) \\
3.3(0.06)\end{array}$ & $\begin{array}{c}16.7(0.06) \\
28.3(.0 .07) \\
18.7(0.06) \\
9.2(0.04) \\
3.6(0.03)\end{array}$ & $\begin{array}{c}16.9(0.05) \\
28.1(0.06) \\
18.5(0.05) \\
9.1(0.04) \\
3.5(0.03)\end{array}$ & $\begin{array}{c}17.0(0.13) \\
28.1(0.16) \\
18.4(0.14) \\
9.1(0.10) \\
3.5(0.07)\end{array}$ & $\begin{array}{c}16.8(0.06) \\
28.1(0.09) \\
18.7(0.06) \\
9.2(0.04) \\
3.6(0.03)\end{array}$ \\
\hline \multicolumn{7}{|l|}{ Geo } \\
\hline University Region & $37.0(0.07)$ & $23.0(0.15)$ & $39.5(0.07)$ & $37.1(0.07)$ & $37.1(0.17)$ & $37.0(0.07)$ \\
\hline Peripheral Region & $38.1(0.07)$ & $44.6(0.18)$ & $36.9(0.07)$ & $38.1(0.07)$ & $38.0(0.17)$ & $38.1(0.07)$ \\
\hline Intermediate Region & $20.6(0.06)$ & $27.6(0.16)$ & $19.4(0.06)$ & $20.6(0.06)$ & $20.6(0.14)$ & $20.6(0.06)$ \\
\hline Remote Region & $4.2(0.03)$ & $4.7(0.08)$ & $4.2(0.03)$ & $4.3(0.03)$ & $4.3(0.07)$ & $4.2(0.03)$ \\
\hline \multicolumn{7}{|l|}{ Deprivation Index } \\
\hline Q1 'Most advantaged' & $15.8(0.05)$ & $12.2(0.1)$ & $16.5(0.06)$ & $15.8(0.05)$ & $15.8(0.13)$ & $15.8(0.06)$ \\
\hline Q2 & $17.7(0.05)$ & $17.6(0.14)$ & $17.7(0.06)$ & $17.7(0.05)$ & $17.6(0.14)$ & $17.7(0.06)$ \\
\hline Q3 & $20.2(0.06)$ & $21.2(0.15)$ & $20.0(0.06)$ & $20.2(0.06)$ & $20.1(0.14)$ & $20.2(0.06)$ \\
\hline Q4 & $21.2(0.06)$ & $23.0(0.15)$ & $20.8(0.06)$ & $21.2(0.06)$ & $21.2(0.15)$ & $21.2(0.06)$ \\
\hline Q5 'Most disadvantaged' & $20.9(0.06)$ & $20.4(0.14)$ & $21.0(0.06)$ & $21.0(0.06)$ & $21.0(0.15)$ & $20.9(0.06)$ \\
\hline Missing values & $4.2(0.03)$ & $5.6(0.08)$ & $4.0(0.03)$ & $4.2(0.03)$ & $4.2(0.07)$ & $4.2(0.03)$ \\
\hline \multicolumn{7}{|l|}{ Resource Utilization } \\
\hline Band & & & & & & \\
\hline Non-User & $3.7(0.03)$ & $4.5(0.07)$ & $3.6(0.03)$ & $3.7(0.03)$ & $3.6(0.07)$ & $3.8(0.03)$ \\
\hline Healthy User & $3.1(0.02)$ & $3.4(0.07)$ & $3.1(0.03)$ & $3.1(0.02)$ & $3.0(0.06)$ & $3.1(0.03)$ \\
\hline Low Morbidity & $15.7(0.05)$ & $16.3(0.13)$ & $15.6(0.06)$ & $15.7(0.05)$ & $15.7(0.13)$ & $15.7(0.06)$ \\
\hline Moderate Morbidity & $59.0(0.07)$ & $58.2(0.18)$ & $59.2(0.07)$ & $59.1(0.07)$ & $59.3(0.18)$ & $59.0(0.07)$ \\
\hline
\end{tabular}




\begin{tabular}{|c|c|c|c|c|c|c|}
\hline High Morbidity & $12.4(0.05)$ & $11.6(0.11)$ & $12.5(0.05)$ & $12.4(0.05)$ & $12.4(0.12)$ & $12.4(0.05)$ \\
\hline Very High Morbidity & $6.0(0.03)$ & $6.0(0.08)$ & $6.0(0.04)$ & $6.1(0.03)$ & $6.1(0.09)$ & $6.0(0.04)$ \\
\hline \multicolumn{7}{|l|}{ Health Status } \\
\hline Diabetes & $16.8(0.05)$ & $16.8(0.13)$ & $16.8(0.06)$ & $16.8(0.05)$ & $16.8(0.13)$ & $16.8(0.06)$ \\
\hline Hypertension & $39.6(0.07)$ & $36.5(0.17)$ & $40.1(0.07)$ & $39.7(0.07)$ & $39.8(0.17)$ & $39.6(0.07)$ \\
\hline $\mathrm{COPD}^{\mathrm{b}}$ & $9.0(0.04)$ & $8.7(0.10)$ & $9.0(0.04)$ & $9.1(0.04)$ & $9.1(0.10)$ & $9.0(0.04)$ \\
\hline Asthma & $4.1(0.03)$ & $3.4(0.06)$ & $4.2(0.03)$ & $4.1(0.03)$ & $4.2(0.07)$ & $4.1(0.03)$ \\
\hline Congestive heart failure & $2.8(0.02)$ & $3.0(0.06)$ & $2.8(0.02)$ & $2.8(0.02)$ & $2.8(0.06)$ & $2.8(0.03)$ \\
\hline Ischemic heart disease & $19.2(0.06)$ & $19.8(0.14)$ & $19.1(0.06)$ & $19.5(0.06)$ & $19.9(0.14)$ & $19.2(0.06)$ \\
\hline $\begin{array}{l}\text { Depression or anxiety } \\
\text { disorder }\end{array}$ & $11.4(0.04)$ & $9.7(0.11)$ & $11.7(0.05)$ & $11.2(0.04)$ & $11.1(0.11)$ & $11.4(0.05)$ \\
\hline \multirow[t]{2}{*}{ Colorectal cancer } & $3.8(0.03)$ & $3.8(0.07)$ & $3.8(0.03)$ & $3.8(0.03)$ & $3.8(0.07)$ & $3.8(0.03)$ \\
\hline & $\begin{array}{c}\text { Total } \\
(n=292,686) \\
\%(S E) \\
\end{array}$ & $\begin{array}{c}\text { FMG } \\
(\mathrm{n}=44,868) \\
\%(\mathrm{SE}) \\
\end{array}$ & $\begin{array}{c}\text { Non-FMG } \\
(\mathrm{n}=247,818) \\
\%(\mathrm{SE}) \\
\end{array}$ & $\begin{array}{c}\text { Total } \\
(n=292,686) \\
\%(S E)\end{array}$ & $\begin{array}{c}\text { FMG } \\
(\mathrm{n}=44,868) \\
\%(\mathrm{SE}) \\
\end{array}$ & $\begin{array}{c}\text { Non-FMG } \\
(\mathrm{n}=\mathbf{2 4 7 , 8 1 8}) \\
\%(\mathrm{SE}) \\
\end{array}$ \\
\hline Breast Cancer & $8.9(0.05)$ & $8.4(0.13)$ & $9.0(0.06)$ & $8.7(0.06)$ & $8.6(0.13)$ & $8.9(0.06)$ \\
\hline Osteoporosis & $44.9(0.09)$ & $42.5(0.23)$ & $45.4(0.10)$ & $44.6(0.09)$ & $43.9(0.23)$ & $45.3(0.10)$ \\
\hline
\end{tabular}

${ }^{\mathrm{b}}$ COPD $=$ Chronic obstructive pulmonary disease

$\mathrm{SE}$ is standard error 


\section{References}

1. Lim LS, Hoeksema LJ, Sherin K, et al. Screening for osteoporosis in the adult U.S. population: ACPM position statement on preventive practice. Am J Prev Med 2009;36(4):366-75. doi: 10.1016/j.amepre.2009.01.013

2. U.S. Preventive Services Task Force, Bibbins-Domingo K, Grossman DC, et al. Screening for Colorectal Cancer: US Preventive Services Task Force Recommendation Statement. JAMA 2016;315(23):2564-75. doi: 10.1001/jama.2016.5989

3. Government of British Columbia. Establishing Priorities among Effective Clinical Prevention Services in British Columbia 2016 [Available from: http://www2.gov.bc.ca/assets/gov/health/about-bc-s-health-care-system/office-of-theprovincial-health-officer/lps-report 2016.pdf accessed Septembre 222017.

4. Ministère de la Santé et des Services sociaux et Institut national de santé publique du Québec. Bilan 10 ans 1998-2008. Programme québécois de dépistage du cancer su sein: Gouvernement du Québec, 2009:49.

5. Brown JP, Josse RG, Scientific Advisory Council of the Osteoporosis Society of C. 2002 clinical practice guidelines for the diagnosis and management of osteoporosis in Canada. CMAJ 2002;167(10 Suppl):S1-34.

6. Desmond L, Hunt R, Champion M, et al. Canadian Association of Gastroenterology and the Canadian Digestive Health Foundation: guidelines on colon cancer screening. Can J Gastroenterol 2004;18(2):93.

7. Sewitch MJ, Fournier C, Ciampi A, et al. Adherence to colorectal cancer screening guidelines in Canada. BMC Gastroenterol 2007;7:39. doi: 10.1186/1471-230X-7-39

8. Canadian Partnership Against Cancer. The 2016 Cancer System Performance Report. Toronto (ON): Canadian Partnership Against Cancer, 2016:128.

9. Zarychanski R, Chen Y, Bernstein CN, et al. Frequency of colorectal cancer screening and the impact of family physicians on screening behaviour. CMAJ 2007;177(6):593-7. doi: 10.1503/cmaj.070558

10. Public Health Agency of Canada. What is the impact of osteoporosis in Canada and what are Canadians doing to maintain healthy bones? Fast Facts from the 2009 Canadian Community Health Survey - Osteoporosis Rapid Response: Canadian Gouvernement, 2010.

11. Ministère de la Santé et des Services sociaux. Programme québécois de dépistage du cancer du sein (PQDCS) - Cadre de référence. Québec: Gouvernement du Québec, 1999:67.

12. Starfield B. Public health and primary care: a framework for proposed linkages. Am J Public Health 1996;86(10):1365-9.

13. Blewett LA, Johnson PJ, Lee B, et al. When a usual source of care and usual provider matter: adult prevention and screening services. Journal of general internal medicine 2008;23(9):1354-60.

14. Bindman AB, Grumbach K, Osmond D, et al. Primary care and receipt of preventive services. J Gen Intern Med 1996;11(5):269-76.

15. Starfield B, Shi L, Macinko J. Contribution of primary care to health systems and health. Milbank Q 2005;83(3):457-502. doi: 10.1111/j.1468-0009.2005.00409.x

16. Provost S, Pineault R, Levesque JF, et al. Does Receiving Clinical Preventive Services Vary across Different Types of Primary Healthcare Organizations? Evidence from a Population-Based Survey. Healthc Policy 2010;6(2):67-84. 
17. Qi V, Phillips SP, Hopman WM. Determinants of a healthy lifestyle and use of preventive screening in Canada. BMC Public Health 2006;6(1):1-8. doi: 10.1186/1471-2458-6-275

18. Hopkins SC, Lenz ER, Pontes NM, et al. Context of care or provider training: the impact on preventive screening practices. Prev Med 2005;40(6):718-24. doi: 10.1016/j.ypmed.2004.09.013

19. Trinite T, Loveland-Cherry C, Marion L. The U.S. Preventive Services Task Force: an evidence-based prevention resource for nurse practitioners. J Am Acad Nurse Pract 2009;21(6):301-6. doi: 10.1111/j.1745-7599.2009.00410.x

20. Kaczorowski J, Hearps SJ, Lohfeld L, et al. Effect of provider and patient reminders, deployment of nurse practitioners, and financial incentives on cervical and breast cancer screening rates. Can Fam Physician 2013;59(6):e282-9.

21. Pandhi N, DeVoe JE, Schumacher JR, et al. Preventive service gains from first contact access in the primary care home. J Am Board Fam Med 2011;24(4):351-9. doi: 10.3122/jabfm.2011.04.100254

22. Carpiano RM, Flocke SA, Frank SH, et al. Tools, teamwork, and tenacity: an examination of family practice office system influences on preventive service delivery. Prev Med 2003;36(2):131-40.

23. Pham HH, Schrag D, Hargraves JL, et al. Delivery of preventive services to older adults by primary care physicians. JAMA 2005;294(4):473-81. doi: 10.1001/jama.294.4.473

24. VanGompel EC, Jerant AF, Franks PM. Primary Care Attributes Associated with Receipt of Preventive Care Services: A National Study. J Am Board Fam Med 2015;28(6):733-41. doi: 10.3122/jabfm.2015.06.150092

25. Smith J, Holder H, Edwards N, et al. Securing the future of general practice: new models of primary care. London: The Nuffield Trust, 2013.

26. World Health Organization. The world health report 2008: primary health care now more than ever. 2008

27. Starfield B. Is Strong Primary Care Good for Health Outcomes? In: Griffin J, ed. The Future of Primary Care: Papers for a Symposium held on 13th September 1995. London: Office of Health Economics 1996.

28. Romanow RJ. Commission on the Future of Health Care in Canada. Shape the future of health care: Interim report. Ottawa, ON: Commission on the Future of Health Care in Canada 2002.

29. Hutchison B, Lévesque JF, Strumpf E, et al. Primary health care in Canada: systems in motion. Milbank Quarterly 2011;89(2):256-88. doi: 10.1111/j.1468-0009.2011.00628.x

30. Clair M. Commission d'étude sur les services de santé et les services sociaux. Les solutions émergentes: Rapport et recommandations: Gouvernment du Québec 2000.

31. Kirby MJL. The Health of Canadians - The Federal Role: Final Report: Standing Senate Committee on Social Affairs, Science and Technology, 2002.

32. Ministère de la Santé et des Services sociaux. Programme de désignation réseau pour les groupes de médecine de famille. Fiche Explicative - Financement GMF-R., 2016.

33. Ministère de la Santé et des Services sociaux. Programme de désignation réseau pour les groupes de médecine de famille: Gouvernement du Québec, 2016.

34. Pomey M-P, Martin E, Forest P-G. Quebec's family medicine groups: innovation and compromise in the reform of front-line care. Canadian Political Science Review 2009;3(4):31-46. 
35. Ministère de la Santé et des Services sociaux. Devenir un GMF : Guide d'accompagnement - Le groupe de médecine de famille : un atout pour le patient et son médecin: les membres du groupe de soutien à l'implantation des groupes de médecine de famille, 2006.

36. Ordre des infirmiers et infirmières du Québec et Fédération des médecins omnipraticiens du Québec. Rapport du Groupe de travail OIIQ/FMOQ sur les rôles de l'infirmière et du médecin omnipraticien de première ligne et les activités partageables, 2005.

37. Vérificateur général du Québec. Vérification de l'optimisation des ressources. Rapport du Vérificateur général du Québec à l'Assemblée nationale pour l'année 2015-2016 2015.

38. Dunkley-Hickin C. Effects of primary care reform in Quebec on access to primary health care services. McGill University, 2014.

39. Régie de l'assurance maladie du Québec. Communiqué - Groupe de médecine famille (GMF) Modalités de facturation: Régie de l'assurance maladie du Québec; 2003 [Available from: http://www.ramq.gouv.qc.ca/fr/professionnels/comm/2002/com124-2.pdf accessed September 112011.

40. Pampalon R, Hamel D, Gamache $\mathrm{P}$, et al. Un indice de défavorisation pour la planification de la santé au Canada. Maladies chroniques au Canada 2009;29(4):199-213.

41. Gauthier J, Haggerty J. Entre adaptabilité et fragilité: les conditions d'accès aux services de santé des communautés rurales et éloignées: rapport de recherche: Direction des systèmes de soins et politiques publiques, Institut national de santé publique Québec 2009.

42. The Johns Hopkins ACG System. Technical Reference Guide Version 10.0: Johns Hopkins University Bloomberg School of Public Health, 2011.

43. Coyle N, Strumpf E, Fiset-Laniel J, et al. Characteristics of physicians and patients who join team-based primary care practices: evidence from Quebec's Family Medicine Groups. Health policy 2014;116(2-3):264-72. doi: 10.1016/j.healthpol.2014.02.010

44. Austin PC, Stuart EA. Moving towards best practice when using inverse probability of treatment weighting (IPTW) using the propensity score to estimate causal treatment effects in observational studies. Statistics in medicine 2015;34(28):3661-79.

45. Provost S, Pineault R, Prud'homme A, et al. Facteurs associés au fait d'avoir ou non un médecin de famille, 2015.

46. Institut national de santé publique du Québec (INSPQ). Système d'information du PQDCS (SI-PQDCS). In: (INSPQ) IndspdQ, ed. Rapport de l'onglet Plan commun de surveillance produit par l'Infocentre de santé publique à l'Institut national de santé publique du Québec. Québec, 2017.

47. Diop M, Fiset-Laniel J, Borgès Da Silva R, et al. Does enrollment in multidisciplinary teambased primary care practice improve adherence to guideline-recommended processes of care? Quebec's Family Medicine Groups, 2002-2010. Health Policy 2017;121(4):37888 .

48. Heroux J, Moodie EE, Strumpf E, et al. Marginal structural models for skewed outcomes: identifying causal relationships in health care utilization. Stat Med 2014;33(7):1205-21. doi: $10.1002 / \operatorname{sim} .6020$

49. Strumpf E, Ammi M, Diop M, et al. The impact of team-based primary care on health care services utilization and costs: Quebec's family medicine groups. Journal of Health Economics 2017;55(September):76-94.

50. Pineault R, Provost S, Borgès Da Silva R, et al. Les changements organisationnels dans les services de santé de première ligne à Montréal et en Montérégie (2003-2010) et leur 
impact sur l'utilisation et l'expérience de soins rapportées par les utilisateurs de services de première ligne. Montrél: Gouvernement du Québec, 2014.

51. Riverin BD, Li P, Naimi AI, et al. Team-based innovations in primary care delivery in Quebec and timely physician follow-up after hospital discharge: a population-based cohort study. CMAJ open 2017;5(1):E28.

52. Léger PT, Strumpf E. Système de paiement des médecins: bref de politique: CIRANO, 2010. 53. Léger PT, Strumpf EC. The Physician Market. In: Culyer AJ, ed. Encyclopedia of Health Economics: Elsevier Science 2014.

54. Dahrouge S, Hogg WE, Russell G, et al. Impact of remuneration and organizational factors on completing preventive manoeuvres in primary care practices. $C M A J$ 2012;184(2):E135-43. doi: 10.1503/cmaj.110407

55. Kiran T, Wilton AS, Moineddin R, et al. Effect of payment incentives on cancer screening in Ontario primary care. Ann Fam Med 2014;12(4):317-23. doi: 10.1370/afm. 1664

56. Li J, Hurley J, DeCicca P, et al. Physician response to pay-for-performance: evidence from a natural experiment. Health Econ 2014;23(8):962-78. doi: 10.1002/hec.2971

57. Charters TJ, Strumpf EC, Sewitch MJ. Effectiveness of an organized colorectal cancer screening program on increasing adherence in asymptomatic average-risk Canadians. BMC Health Serv Res 2013;13:449. doi: 10.1186/1472-6963-13-449

58. Kiran T, Glazier RH, Moineddin R, et al. The Impact of a Population-Based Screening Program on Income- and Immigration-Related Disparities in Colorectal Cancer Screening. Cancer Epidemiol Biomarkers Prev 2017;26(9):1401-10. doi: 10.1158/10559965.EPI-17-0301 [published Online First: 2017/06/20]

59. Petrik AF, Green BB, Vollmer WM, et al. The validation of electronic health records in accurately identifying patients eligible for colorectal cancer screening in safety net clinics. Fam Pract 2016;33(6):639-43. doi: 10.1093/fampra/cmw065 [published Online First: 2016/07/30]

60. Grimes DA. Epidemiologic research using administrative databases: garbage in, garbage out. Obstetrics \& Gynecology 2010;116(5):1018-19.

61. Glazier RH, Zagorski BM, Rayner J. Comparison of primary care models in Ontario by demographics, case mix and emergency department use, 2008/09 to 2009/10: Institute for Clinical Evaluative Sciences 2012.

62. Ministère de la Santé et des Services sociaux. Programme québécois de dépistage du cancer du sein. Cadre de référence.: Gouvernement du Québec, 1996:67. 